\title{
Beyaz Eşyalarda Enerji Sınıflandırmasının İncelenmesi
}

\author{
Ahmet Fertelli $^{1 *}$, Oğuzhan Pektezel ${ }^{2}$ \\ ${ }^{I}$ Sivas Cumhuriyet Üniversitesi, Mühendislik Fakültesi, Makine Mühendisliği Bölümü, Sivas, Türkiye. \\ ${ }^{2}$ Tokat Gaziosmanpaşa Üniversitesi, Mühendislik ve Mimarlık Fakültesi, Makine Mühendisliği Bölümü, \\ Tokat, Türkiye. \\ *fertelli@cumhuriyet.edu.tr,oguzhan.pektezel@gop.edu.tr
}

Özet

Gelişmekte olan ülkemizde, artan enerji talebinin karşılanması için yeni yatırımlar yapılmakla beraber, mevcut enerji kapasitesinin tasarruflu ve verimli kullanılmasına yönelik çalışmalar hız kazanmıştır. Bu çerçevede beyaz eşyalarda enerji sınıflandırılmaları yapılarak, elektrik tüketimi az olan cihazların üretimleri gerçekleştirilmiştir. Bu çalışmada, farklı beyaz eşya markalarına ait çamaşır makinesi, kurutma makinesi, buzdolabı ve derin dondurucu ürünlerinin enerji sınıflandırmaları, elektrik tüketim değerleri ve fiyat değişimleri incelenmiştir. Sonuçlarda, daha verimli cihazların satış fiyatlarının yüksek olduğu, elektrik tüketimi yüksek ürünlere göre geri ödeme sürelerinin 6 yıl -18,5 yıl aralığında değiştiği görülmüştür.

Anahtar Kelimeler: enerji verimliliği, beyaz eşya, enerji sınıflandırması.

\section{Investigation of Energy Classification in White Goods}

\begin{abstract}
In our improving country, besides of new investments carried out to meet increasing energy demand, studies made for economic and efficient use of current energy capacity have accelerated. Within this scope performing energy classification in white goods, production of low electricity consuming devices was carried out. In this study, energy classifications, electricity consumption values and price changes of washing machines, drying machines, fridges and deep freezers belonging different white good brands were investigated. As a result, it was observed that more efficient devices had higher sale prices and showed 618,5 years of payback period when compared to those devices consuming high electricity.
\end{abstract}

Keywords: energy efficiency, white good, energy classification. 


\section{GíRiş}

Ülkemizde, hem artan sanayi üretimleri hem de gelişen konfor şartlarının gerektirdiği enerji talebi günden güne hızla artmaktadır. Artan enerji talebinin karşılanması için yoğun bir şekilde yapılan yatırımların yanında, mevcutta kullanılan enerjinin sanayi ve bireysel bileşenleri tarafından da verimli ve aynı zamanda da etkili kullanılması büyük önem taşımaktadır. Enerji verimliliği, enerji tasarrufu, bilinçli tüketim, bilinçli tercih edilen cihazlar göz önünde bulundurularak yapılan doğru yatırımlar hem bireysel hem de ülke kazancı açısından önemli bir rol oynamaktadır. Ülkemizde 2018 yılındaki elektrik tüketimi 304,2 milyar kWh olarak gerçekleşmekle beraber, 2023 yılında tüketimin 375,8 TWh değerine kadar artmas1 beklenmektedir [1]. 2023 yılında ülke olarak hedeflerimizden birisi enerji verimliliği ile enerji tasarrufunun kullanılmasının sağlanarak enerji ihtiyacının yerli ve milli kaynaklarla sağlanmasıdır. Ayrıca enerji yoğunluğunun da \% 20-30 oranlarında azaltılması hedeflenmektedir. Bu nedenle, Ulusal Enerji Verimliliği Eylem Planı (2017-2023) 02/01/2018 tarihinde yürürlüğe girerek, 2023 yılında birincil enerji tüketiminde \%14 azalma ile 2033 yılında 30,2 milyar dolarlık bir tasarruf öngörülmektedir [1]. Yapılan analizlerde ülkemizde 2017 ve 2018 yıllarında enerji verimliliğine 1.35 milyar ABD Doları yatırım yapıldığı ve bunun sonucunda yaklaşık 900 bin tep enerji tasarrufu sağlandığı hesaplanmıştır [2]. Türkiye de birincil enerji tüketimin \%25'i konutlarda gerçekleşmektedir [3]. Çok önemli bir oranda gerçekleşen konut enerji tüketiminin azaltılması aynı zamanda da verimli ve tasarruflu teknolojilerin kullanılması eylem planı açısından da büyük önem arz etmektedir. Bunun için verimli ve az enerji harcayan cihazların kullanımı [4], müşteri tercihlerinde ön plana çıkarılması ve çeşitli teşvik sistemlerinin bu temel tüketim bilincini desteklemesi hedef noktalarının gerçekleştirilmesi açısından son derece önemlidir. Mesken elektrik tüketimleri incelendiğinde, en büyük elektrik tüketim oranın bireylerin temel ihtiyaçlarını karşılayan beyaz eşyalardan kaynaklandığı görülmektedir. Bunlar, çamaşırı makinesi, kurutma makinesi, bulaşık makinesi, buzdolabı ve derin dondurucu cihazlardır. Günümüz konfor koşullarında cihazların bazıları gün içerisinde tüm zamanlarda, bazıları ise belirli saat aralıklarında sürekli çalışmaktadır. Yapılan bu çalışmada Türkiye'de satış yapan birçok firma tarafindan üretilen beyaz eşyalar, firmaların kendi özelliklerine göre belirledikleri kategoriler içerisinde ve enerji sınıflandırılmalarına göre incelenmiştir. Her firmanın kendi kataloglarında belirttikleri değerlere göre karşılaştırmalar ve hesaplamalar yapılmıştır. Ürünler çok çeşitli ve farklı özelliklerde olsalar da, analizler için ürünlerin temel özellikleri (enerji sınıfı, yıkama kapasitesi, devir sayısı ve soğutucu hacmi) incelenerek karşılaştırma yapılmıştır. Çamaşır makineleri yıkama (8 kg, $9 \mathrm{~kg}$ ve $10 \mathrm{~kg}$ ) ve devir kapasitelerine $(1000,1200$ ve 1400 devir) göre, kurutma makinelerinde ise $7 \mathrm{~kg}$ ve $8 \mathrm{~kg}$ kapasiteli makineler için analizler yapılmıştır. Buzdolaplarında $470 \mathrm{~L}$ - $510 \mathrm{~L}$ hacmindeki ürünler, derin dondurucularda ise 220L $-250 \mathrm{~L}$ arasındaki değişen hacimlerdeki ürünler incelenmiştir. Çamaşır yıkama makinelerinde $8 \mathrm{~kg}$ ve 1000 devir için L1, L2, B1, B2, C, E, F1, F2, M markalar1, $8 \mathrm{~kg}$ ve 1200 devir için L, B, H, C, E, F markaları, 9 kg ve 1000 devir için J, L1, L2, B1, B2, C, E, M markaları, 9 kg ve 1200 devir için J, L, B, C, E, M, H markaları, $10 \mathrm{~kg}$ ve 1200 devir için L, B1, B2, F, M markaları, $10 \mathrm{~kg}$ ve 1400 devir için ise L1, L2, C, H markaları incelenmiştir. Kurutma makinelerinde $7 \mathrm{~kg}$ için L1, L2, B, F markaları, 8 kg için ise C1, C2, C3, L, M1, M2, J, E, B markaları incelenmiştir. Buzdolaplarında J1, J2, C1, C2, L, B, E1, E2, H markaları incelenirken derin dondurucularda ise J, L1, L2, B, E, M, K1, K2 markalar1 incelenmiştir. Bu notasyonda harflerin yanlarında bulunan 1, 2 ve 3 rakamları aynı markanın aynı özellikte fakat farklı enerji sınıfında bulunan diğer makinelerini temsil etmektedir.

\section{BULGULAR VE TARTIŞMA}

Elde edilen sonuçlarda, firma ürünlerinin satış fiyatları ve enerji tüketim değerleri incelenmiştir. Şekil 1'de farklı yük ve devir kapasitelerindeki çamaşır makineleri için firmalara ait fiyat ve tüketim değerleri 
grafikleri gösterilmektedir.Tüm grafiklerde aynı enerji sınıfindaki ve aynı tip ürünlerde hem satış fiyatlarının çok değişken olduğu, hem de enerji tüketim değerlerinin farklı olduğu görülmektedir. $8 \mathrm{~kg} 1000$ devir - 1200 devir ürünler için B2, C ve E markalı ürünlerde tüketim değerlerinin birbirlerine çok yakın olmasına rağmen, fiyatların 2300-3150 € arasında değiştiği görülmektedir. Aynı markanın iki farklı elektrik tüketen ürünü olmasına rağmen, daha düşük enerji tüketen modelin diğerine göre daha pahalı olduğu görülmektedir. \% 32,5 tüketimde azalma varken, fiyatta \% 18,3 artış gerçekleşmiştir.

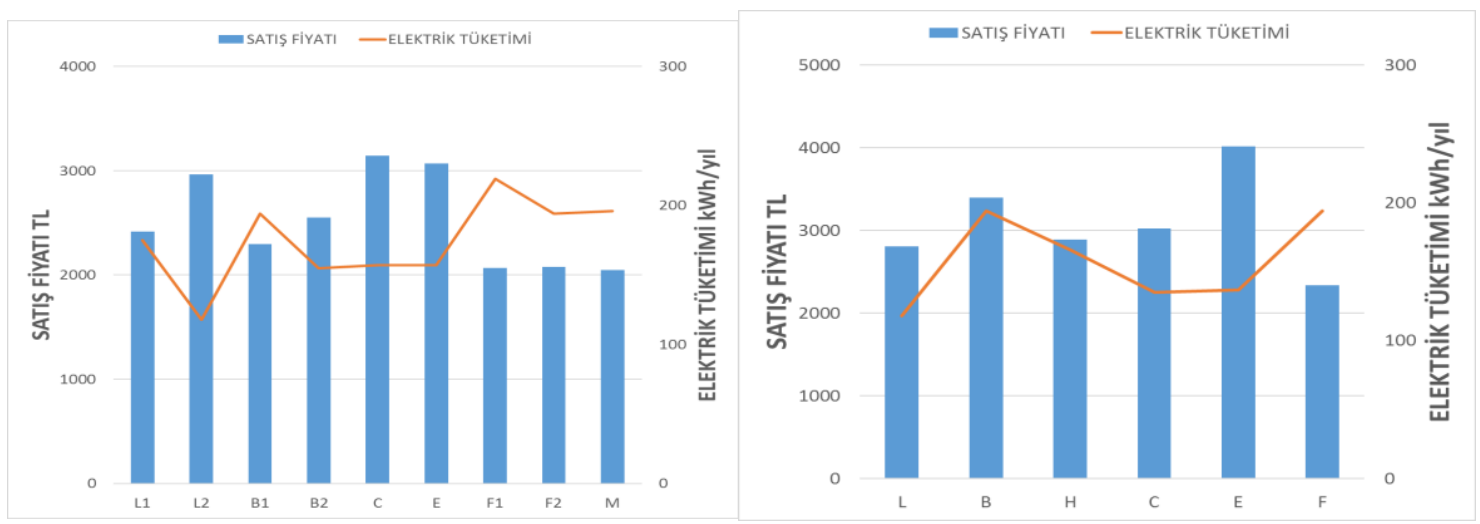

a) $8 \mathrm{~kg}-1000$ devir

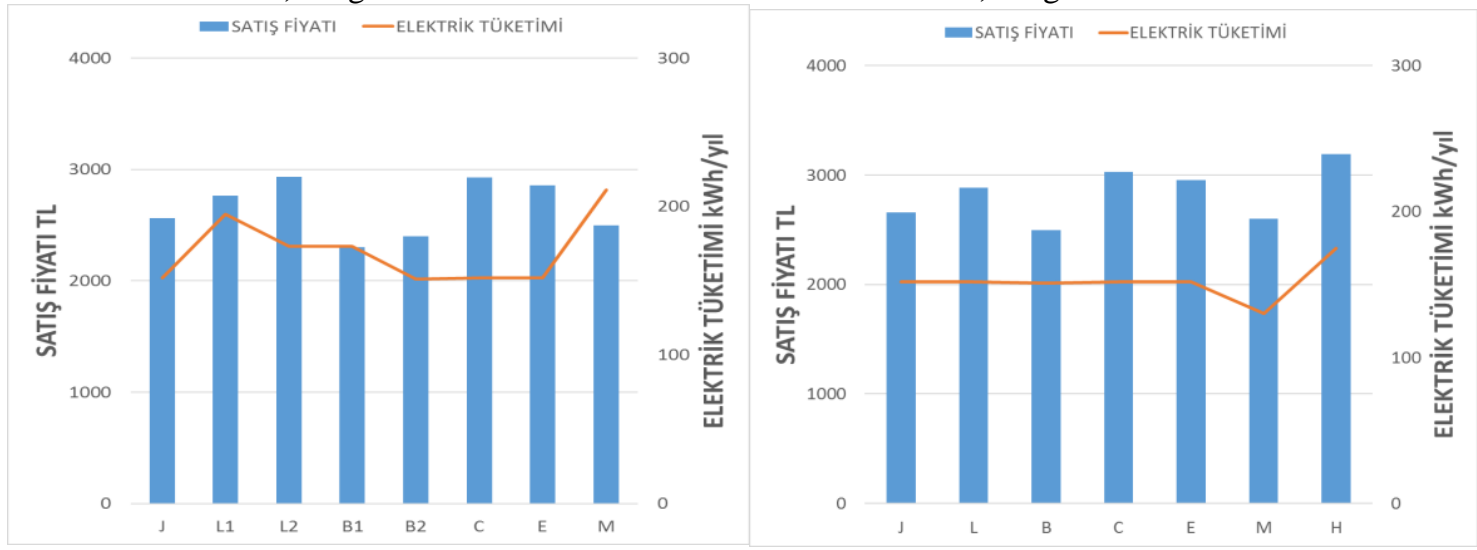

c) $9 \mathrm{~kg}-1000$ devir

d) $9 \mathrm{~kg}-1200$ devir

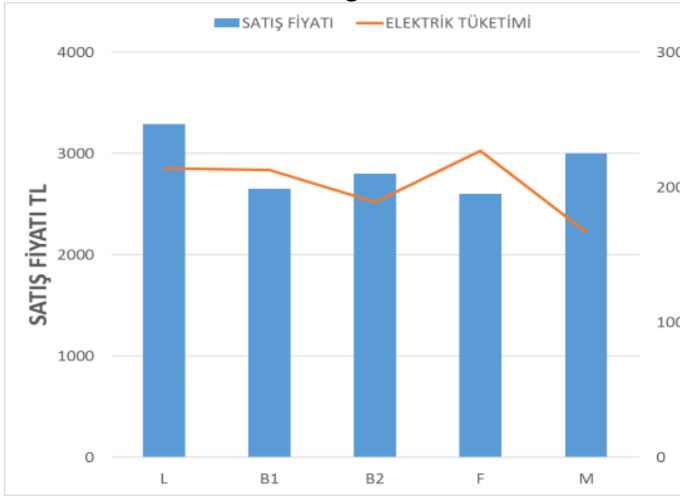

e) $10 \mathrm{~kg}-1200$ devir

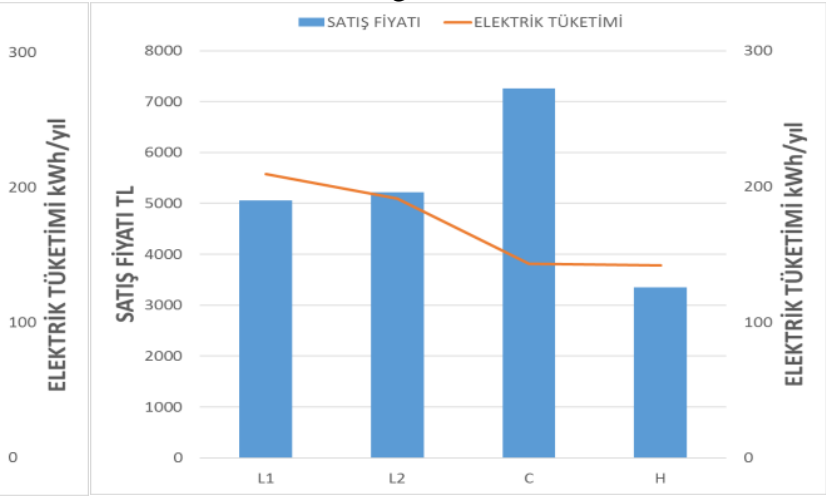

f) $10 \mathrm{~kg}-1400 \mathrm{devir}$

Şekil 1. Çamaşır Makineleri İçin Fiyat-Elektrik Tüketimi Değişimi

Burada da elektrik tüketimi az ürünlerin fiyat ile değişiminin ters orantılı devam ettiği görülmektedir. $9 \mathrm{~kg}$ çamaşır makinelerinde ise özellikle 1200 devirlik ürünlerde elektrik tüketimlerinin birçok markada sabit değerlerde bulunduğu, fiyat değişimlerinin ise markalar arasında daha az farklarla gerçekleştiği tespit 
edilmiştir. $10 \mathrm{~kg}$ makinelerde 1200 devir ve 1400 devir ürünler incelenmiş olup, elektrik tüketim değerlerinin $140 \mathrm{kWh}$ - $225 \mathrm{kWh}$ değerleri arasında değiştiği, düşük elektrik tüketimli ürünlerdeki yüksek fiyat stratejisinin burada da devam ettiği gözlenmektedir.

$7 \mathrm{~kg}$ ve $8 \mathrm{~kg}$ çamaşır kurutma makineleri Şekil 2'den incelendiğinde, ürünlerdeki elektrik tüketim değerleri arasındaki farkların çok fazla olduğu, düşük tüketimli ve yüksek tüketimli ürünler arasında $7 \mathrm{~kg}$ için \% 32,25 fiyat farkı oluştuğu görülmektedir. Kapasite artırıldığında da değişimin yaklaşık \% 32 civarında gerçekleştiği görülmektedir. Soğutma amaçlı kullanılan cihazlardan buzdolaplarında ve derin dondurucularda ise soğutma kapasitelerindeki farklılardan dolayı oluşabilecek farklı enerji tüketim değerlerinin oluştuğu, düşük ve yüksek tüketimli ürünlerdeki fiyat değişimlerinin çamaşır makinelerine göre daha az olduğu tespit edilmiştir.

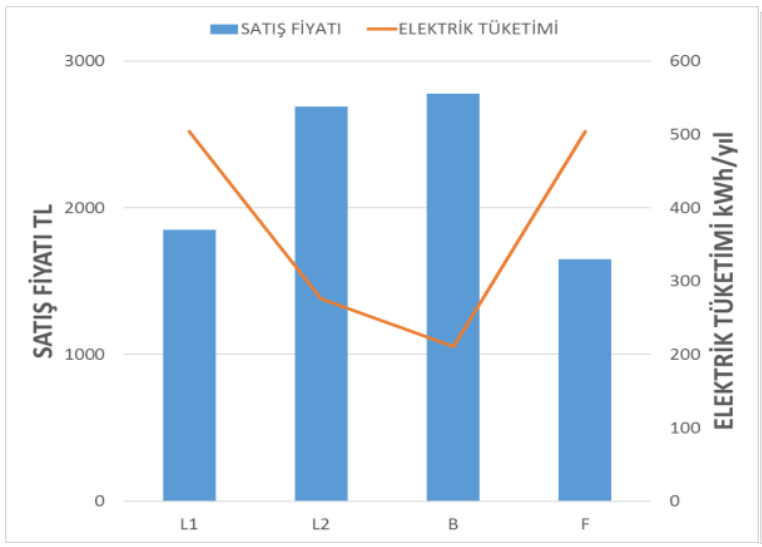

a) $7 \mathrm{~kg}$

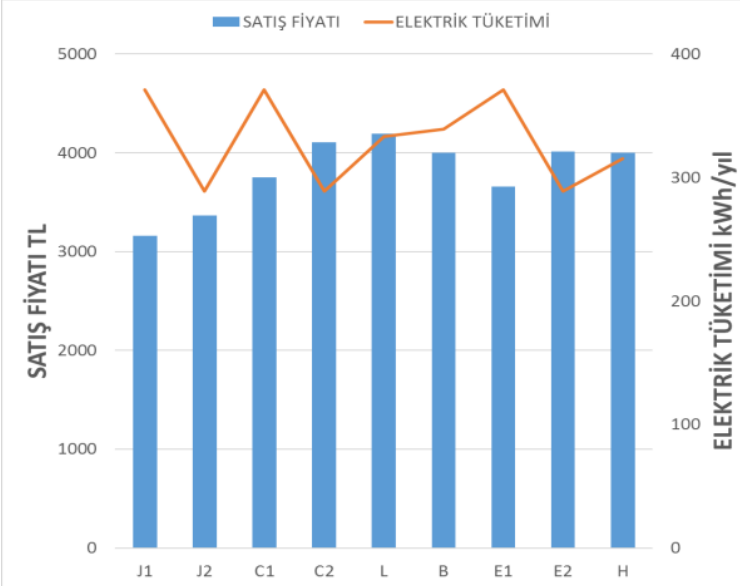

c) $470-510 \mathrm{~L}$

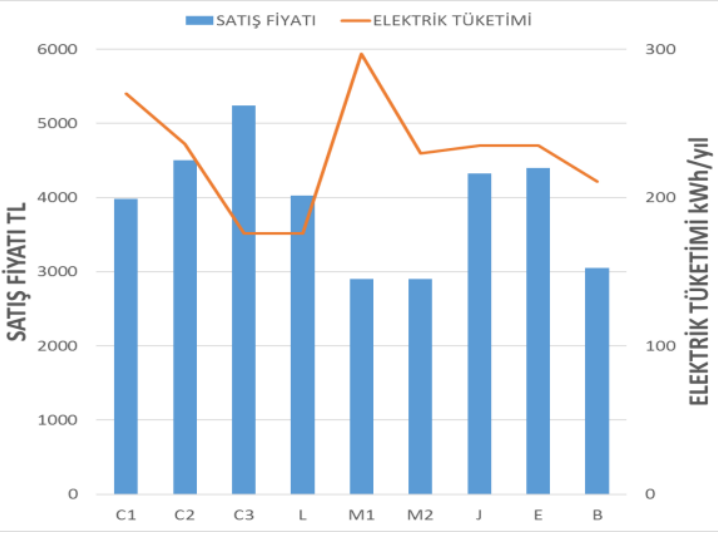

b) $8 \mathrm{~kg}$

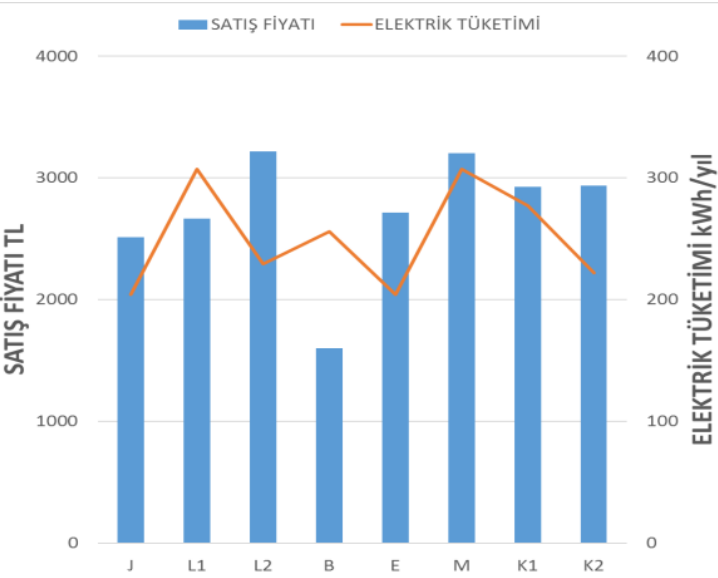

d) $220-250 \mathrm{~L}$

Şekil 2. Fiyat-Elektrik Tüketimi Değişimi a-b) Çamaşır Kurutma Makineleri c) Buzdolapları d) Derin Dondurucular

Tüm beyaz eşyalar için hesaplanan geri ödeme süreleri Tablo 1'de gösterilmektedir. Fiyat - enerji tüketim ilişkisindeki düzensiz dağılımdan dolayı hem firmaların kendi ürünleri içerisinde hem de farklı firmalar arasında farklı geri ödeme sürelerinin gerçekleştiği görülmektedir. Çamaşır makinelerinde 0,6 yıl -14,8 yıl arasında değişen geri ödeme süreleri kurutma makinelerinde 0 yıl - 20,3 yıl arasında değişmektedir. Buzdolaplarında 3,8 yıl - 6,5 yıl arasında daha düşük düzeyde geri ödeme süreleri varken, derin dondurucularda 0,3 yıl - 10,6 yıl arasında değiştiği görülmektedir. 
Tablo 1. Beyaz Eşyaların Geri Ödeme Süresi

\begin{tabular}{|c|c|}
\hline Marka & Geri Ödeme Süresi (Yll) \\
\hline L1 & 14,81 \\
\hline B1 & 9,71 \\
\hline F1 & 0,61 \\
\hline L1 & 12,67 \\
\hline B1 & 6,55 \\
\hline B1 & 9,35 \\
\hline L1 & 13,89 \\
\hline L1 & 5,58 \\
\hline C1 & 20,31 \\
\hline C2 & 18,69 \\
\hline M1 & 0 \\
\hline Marka & Geri Ödeme Süresi (Yll) \\
\hline J1 & 3,81 \\
\hline C1 & 6,56 \\
\hline E1 & 6,47 \\
\hline L1 & 10,68 \\
\hline K1 & 0,36 \\
\hline
\end{tabular}

\section{SONUÇ}

Ülkemizde son yıllara beyaz eşyalarda enerji verimli ürünlerin üretilmesi enerji tasarrufu ve verimliliği açısından çok önemlidir. Bu ürünlerin kullanıcılar tarafından tercih edilip çok enerji tüketen gerek eski ürünlerin yenileri ile değiştirilmesi, gerekse yeni ürün alımında tercih edilebilir olması beklenen fayda ve hedeflenen amaçlar için önemlidir. Bu çalışmada günlük yaşantıda bireyler tarafindan kullanılan beyaz eşyaların elektrik tüketim ve satış fiyatları arasındaki ilişki değerlendirilmiştir. En verimli ürünlerin en yüksek fiyata sahip olduğu, geri ödeme sürelerinin çamaşır makinelerinde en fazla 14,8 y1l, kurutma makinelerinde 20,3 yıl, buzdolabı ve derin dondurucularda ise 10,6 y1la kadar arttı̆̆ görülmektedir. Bu şekliyle geri ödeme süreleri cihazların kullanım ömürlerine yakın ve daha fazladır. Dolayısıyla tüketicinin verimli ürünleri tercih etmesi noktasında teşvik edici değildir. Ürün, fiyat ve verimlilik dengesinin daha makul düzeylerde olması için firma ve tüketici nezdinde daha teşvik edici ve ekonomik tedbirlerin oluşturulması büyük önem arz etmektedir.

\section{REFERANSLAR}

[1] https://www.enerji.gov.tr/tr-TR/Sayfalar/Elektrik

[2] https://www.enerji.gov.tr/tr-TR/Sayfalar/Enerji-Verimliligi

[3] Koç, A., Yağlı, H., Koç, Y., ve Uğurlu, İ. (2018). "Dünyada ve Türkiye'de Enerji Görünümünün Genel Değerlendirmesi." Mühendis ve Makine 59(692):86-114.

[4] Cengiz, M., Girginer, N. (2012). "Konjoint Analizi İle Tüketici Tercihlerinin Belirlenmesi: Buzdolab1 Örneği.” Eskişehir Osmangazi Üniversitesi İİBF Dergisi 7(1):269-290. 